\title{
Egophoric marking and person indexation in Japhug
}

\author{
Guillaume Jacques \\ Southwest University (ICLD) \& CNRS (CRLAO)
}

Japhug, like other Gyalrong languages, is one of the very few languages with both a full-fledged person indexation system and an egophoric evidential category. A detailed account of the uses and meanings of the Egophoric and its interaction with person is thus of interest to the typology of evidential systems. This paper describes the uses of Egophoric marking in Japhug and of the other two evidential categories with which it contrasts (Factual and Sensory), as well as their interaction with person indexation. Due to the limited distribution of the Egophoric in Japhug (it only occurs in present contexts), the present paper exclusively focuses on the uses of evidentials with stative verbs in present (imperfective) contexts, where minimal pairs are available in the corpus.

Keywords: Egophoric, Factual, Sensory, mirative, Hybrid Indirect Speech, conjunct/disjunct, person indexation

\section{Introduction}

The interaction between Evidentiality and Person is a well established phenomenon (Aikhenvald 2004, 217-238; Aikhenvald 2015; Sun 2018), and Egophoric marking, a phenomenon documented in the Himalayas, South America, the Caucasus and Highland New Guinea ${ }^{1}$ is one of the most person-sensitive evidential categories.

Very few languages have both person indexation and egophoric marking; none of those included in the forthcoming volume on egophoricity (Floyd et al. 2018)

1. Recent references include Tournadre (2008), Hill \& Gawne (2017), DeLancey (2018), Creissels (2008), Curnow (2002), San Roque \& Loughnane (2012) and San Roque et al. (2017); earlier work such as Yukawa (1971) and Bendix (1974) had correctly described the phenomena before the term 'Egophoric' was coined by Tournadre (1996). A distinct research tradition refers to the contrast between Egophoric and other evidential categories as 'conjunct/disjunct' (Hale 1980; DeLancey 1990).

https://doi.org/10.1075/lali.00047.jac

Language and Linguistics 20:4 (2019), 515-534

ISSN 1606-822X / E-ISSN 2309-5067

This is an open access article under a CC BY 4.0 license. 
have person indexation, and in the Sino-Tibetan family, while languages with egophoric marking such as Newar, Pumi (Daudey 2014) and Bunan (Widmer \& Zemp 2017) have remnants of person indexation completely or partially reanalyzed as evidential categories, the only language group where both a fully fledged person indexation system and an evidential system containing an egophoric category are both present is the Gyalrong branch of Sino-Tibetan, comprising Situ, Japhug, Tshobdun and Zbu (Sun 2018). While previous work has partially described the use of evidential categories in Gyalrong languages (see in particular Lin 2003; Sun 2003; Jacques 2017: 617-620), much descriptive work is still needed before these languages can be profitably used by typologists working on evidentiality.

TAME systems in Gyalrong languages are highly complex, comprising more than ten basic TAME forms, augmented by periphrastic TAME categories and secondary affixes. A satisfactory description of the TAME of any such language therefore requires a book-length monograph. The present study is of more limited scope: studying the tripartite evidential contrast in the present imperfective of stative verbs. This choice has three motivations.

First, the tripartite evidential contrast between Factual, Sensory and Egophoric only exists in the present, since the Egophoric marker is incompatible with past and future tenses (see $\$ 1$ ). Second, stative verbs have fewer TAME distinctions than dynamic verbs. Third, stative verbs, having only one core argument, present fewer interactions between person and evidentiality than transitive verbs.

By focusing on such a restricted topic, we isolate the evidential contrast, and study minimal pairs which have exactly the same tense, aspect and modality parameters, to avoid any possible interference which could make the analysis of the semantic contrasts more difficult.

This paper studies the tripartite evidential contrasts in the three main constructions relevant to the topic at hand: declarative clauses, interrogative clauses, and reported speech. It systematically discusses the semantic differences between the three categories and their relationship with person marking.

As evidential markers require a very clear context, elicited examples have been avoided in the present paper, which contains data coming either from narratives or from conversations. ${ }^{2}$

2. The examples are taken from a corpus that is progressively being made available on the Pangloss archive (Michailovsky et al. 2014, http://lacito.vjf.cnrs.fr/pangloss/corpus/list_rsc. php?lg=Japhug). Some examples are taken from stories translated from Chinese (systematically identified by the label "translation" before the reference of the story), but have been rechecked thoroughly and no example suspect of containing a calque from Chinese has been included. Note that since Mandarin has neither evidential marking nor person indexation, calquing would have little direct interference with the topic at hand in any case. 


\section{Morphological categories}

This section describes the morphology of evidential categories in the present tense in Japhug, as well as person indexation. The meaning of these categories is discussed in $₫ 2$ and $₫ 3$.

\subsection{The tripartite system}

Stative verbs have only three distinct forms in the present imperfective: the Factual Non-Past, the Sensory Imperfective, and the Egophoric Imperfective Present, henceforth referred to as Factual, Sensory, and Egophoric. Although the three forms require stem alternation in the case of transitive verbs with singular subject and third person object (see Sun 2000; Jacques 2014: 267), no stem alternation occurs with stative verbs. Therefore, these forms are only marked by affixation for this verbal category.

The Sensory form is built by combining the stem with the prefix $n u$ - (in the negative $m u \dot{u} j$-), the Egophoric with the prefix $k u$ - (its negative form is $m u-k u$-), and the Factual which has no prefix, and consists of the bare stem (its negative form is marked by the prefix $m \gamma$-), as indicated in Table 1 . Some verbs also form their Imperfective with the prefixes $n u$ - or $k u$-, and have thus syncretisms (for instance, the Imperfective 3sG of rga 'be happy' and $\eta g r r$ 'be narrow' are $n u-r g a$ and $k u$ - $y g r r$ respectively, and identical with the corresponding Sensory and Egophoric forms respectively).

Table 1. The three present evidential forms of stative verbs in Japhug

\begin{tabular}{|c|c|c|}
\hline Form & $\begin{array}{l}\text { Regular stative verb } \\
\text { (pe 'be good') }\end{array}$ & $\begin{array}{l}\text { Existential verbs } \\
\text { ( } t u \text { 'exist') }\end{array}$ \\
\hline Factual & pe & $t u$ \\
\hline Factual, negative & $m \gamma-p e$ & me \\
\hline Sensory & nu-ре & yrzu \\
\hline Sensory, negative & múij-pe & maye \\
\hline Egophoric & $k u-p e$ & $k u-t u$ \\
\hline Egophoric, negative & $m u-k u-p e$ & ku-me \\
\hline
\end{tabular}

The existential verbs $t u$ 'exist' and $m e$ 'not exist' have suppletive Sensory forms $y r z u$ 'exist.sens' and maye 'not exist.sens'. ${ }^{3}$ The suppletive verbs have irregular second person forms ( $y$ rtrzu $u$ and mataye respectively, see Jacques 2012).

3. Thus, despites the fact that $m e$ forms its Imperfective with the prefix $n u$-, there is no ambiguity with the Sensory. 
A fourth category is also possible in the present tense, the Imperfective, but it has an inchoative meaning, and turns a stative verb into a dynamic one (for instance the imperfective $t u$-pe IPFv-be.good means 'it becomes better/good); it will therefore not be considered in this paper. ${ }^{4}$

The Sensory and the Factual are not restricted to present tense. Sensory is also used in past tense imperfective, and the Factual in future tense, with various aspectual meanings. These uses will not concern us in the present paper.

In addition to verbal morphology, evidentiality and epistemic modality are partially marked by sentence final particles such as $k^{h} i$ 'hearsay' and thay 'probably'. The interaction between these particles and the three-way evidential marking is deferred to further research.

\subsection{Person indexation}

Stative verbs are a subclass of intransitive verbs, and can only index one argument, the intransitive subject (S), following the paradigm in Table 2 (the symbol $\Sigma$ represents the verb stem, following the kirantologist tradition initiated by van Driem 1993). Third person singular is zero-marked. The possessive prefixes, found on nouns and on some non-finite verb forms, are also indicated for comparison.

Table 2. Intransitive person indexation and possessive paradigms

\begin{tabular}{lll}
\hline Person & Indexation affixes & Possessive prefixes \\
\hline $1 \mathrm{SG}$ & $\sum-a$ & $a-$ \\
$1 \mathrm{DU}$ & $\sum-t_{6 i}$ & $t 6 i-$ \\
$1 \mathrm{PL}$ & $\sum-j$ & $j i-$ \\
\hline $2 \mathrm{SG}$ & $t u-\Sigma$ & $n \gamma-$ \\
2DU & $t u-\sum-n d z i$ & $n d z_{0}-$ \\
2PL & $t u-\sum-n u$ & $n u-$ \\
\hline 3SG & $\sum$ & $m-$ \\
3DU & $\sum-n d z i$ & $n d z i-$ \\
3PL & $\sum-n u$ & $n u-$ \\
\hline
\end{tabular}

Although stative verbs can only index one argument, some of them are semi-transitive and can take a second absolutive argument (noun phrase or complement clause), for instance $m k h \gamma z$ 'be expert' (Jacques 2016a: 275):

4. This is actually, together with the fact of having an infinitive in $k u$-instead of $k \gamma$ - (Jacques 2016a: 227), one of the defining properties of stative verbs in Japhug. 
(1) $u$-nтав jr-ku-ye nu $60 \eta \beta z u$

3sG.POss-husband PFV-NMLZ:S/A-come[II] DEM carpentry

$m k^{h} z z \quad$ t6e

be.expert:FACT LNK

'Her husband (who came to live in her family) is very good at carpentry.'

(14-tApitaRi, 273)

Semi-transitive stative verbs are however very few, and the second absolutive argument is nearly always third person. Exceptions like (2) with a second person additional argument are rare and are not considered in this paper. For the purpose of this study, only the person of the argument indexed on the verb will be taken into account.
(2) $a-b i$, nrzo uu-nú-fse-a
1sG.POss-younger.sibling 2sG QU-SENS-be.like-1sG
'Sister, do I look like you?'

(2003kongzong, 293)

\section{Declarative clauses}

\subsection{Factual}

Used in the present with stative verbs, the Factual expresses a fact regarded as true by the speaker or belonging to generally accepted knowledge.

It is compatible with all persons, including 1SG (Examples (3) and (4), with the suffix -a), 2sG (Example (5), with the prefix tu-) and 3sg (Example (6), no affix).

With the first person, the Factual can be used to tell something about oneself that the addressee may not know, but which all persons familiar with the speaker are aware of, as in (3). In Example (4), the Factual is appropriate to express the overconfidence of the speaker in his abilities, which he believes to be obvious and well-known.

(3) azo nura fse-a t6e ygu-a t6e,

1SG DEM:PL be.like:FACT-1SG LNK be.poor:FACT-1SG LNK

'I am poor like that.' （translation, 150824 kelaosi, 55)

(4) azo kunr wuma zo $6 q r a s-a \quad$ t6e, a-ku-nußlu

1sG too really EMPH be.smart:FACT-1SG LNK 1sG-NMLZ:S/A-cheat $k u-c^{h} a \quad m e$,

NMLZ:S/A-can not.exist:FACT

'I am very smart too, nobody can cheat me.' (translation, 150830 afanti, 120)

In (5), the Factual occurs with a verb in the second person to state a fact about the addressee considered to be obviously true by the speaker: 
(5) nrzo stu zo tu-mkhrz t6e, t6e nrzo 6-tr-nrme

2sG most EMPH 2-be.expert:FACT LNK LNK 2sG TRANSLOC-IMP-do[III]

'You are the best at it, do it!'

(translation, 150822 laoye zuoshi zongshi duide, 37)

In (6), the Factual is used with two adjectival verbs to describe facts about the swallow that the speaker is relatively confident in and consider to be generally well known. This use is in contrast with that of the Sensory to report facts which the speaker has less confidence in, for instance concerning animals he/she has never seen (see $\$ 2.2$ ).

(6) wuma zo pe t6e, srindrt t6e, really EMPH be.good:FACT LNK be.cute:FACT LNK '(The swallow) is very nice, it is cute.'

(03-mWrmWmbjW, 6)

\subsection{Sensory}

The Sensory is used to express access to information through any of the senses, most commonly vision, but also hearing (7), touch (8), smell (9) and taste (10). It implies the discovery of a previously unknown fact or confirmation of an uncertain fact.

(7) tu-mbri t6e u-skrt wuma zo nu-mpбrr IPFV-cry LNK 3sG.POSS-voice really EMPH SENS-be.beautiful 'When it cries, its voice is very beautiful.'

(translation, 04-cuiniao, 26)

(8) nú-wy-nrmrle toe nu-mpu

IPFV-INV-touch LNK sENS-be.soft

'It is soft to the touch.'

(19 khWlu, 25)

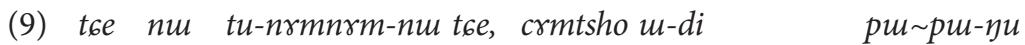
LNK DEM IPFV-smell-PL LNK musk 3sG.POSS-smell COND PST.IPFV-be $n \gamma, u-d i \quad$ nu-mnrm t6e nunu t6u $u-f s a$

LNK 3sG.POss-smell sENs-be.smell LNK DEM LOC 3sG.POSS-snare tu-ta-nu nu-ggrrl

IPFV-put-PL SENS-be.usually.the.case

(The hunters) smell (the places where they find deer fur); if it is the smell of musk, it is very strong. And they put the snare there.

(27 kikakCi, 68)

(10) tú-wy-ndza toe wuma zoo nu-mum nu-ti IPFV-INV-eat LNK really EMPH SENS-be.tasty SENS-say

'She said: '(These ferns, prepared this way) are very nice to eat'.

(said just after eating them; conversation 14.05.10) 
Although in the above examples there is no implication that the person producing the sound or the objects mentioned in the sentences are not visible to the speaker, in these contexts vision is largely irrelevant to determine the property in question, and there is not ambiguity as to which sensory channel was responsible for obtaining the information.

Like the Factual, the Sensory can occur with all persons, including the 1sG (Examples (12) and (13)) and the second person (Example (11)).

With second person subjects, the Sensory is very commonly used to state a fact about the addressee that the speaker noticed (not something he knew previously). For instance, in contrast to (5) above in which the addressee's (recent) actions are irrelevant, a sentence such as (11) can be used if the speaker witnessed something revealing the proficiency of the addressee.

(11) $n u-t u-m k^{h} z z$

SENS-2-be.expert

'You are good at it.'

(heard in several conversations)

With first person subjects, the Sensory is not rare. It is common with verbs such as rga 'be happy ${ }^{5}$ whose intransitive subject is the experiencer, as in (12). ${ }^{6}$
$n \gamma-t 6 m$
tr-sci
t6e nu-pe
t6e papa, azo

2sG.POSs-child PFV-born LNK SENS-good LNK good 1sG

num-rga-a

SENS-be.happy-1sg

'It is nice that your son is born, I am happy.' (Tshendzin, conversation, 2013)

With non-experiencer adjectival stative verbs, it can occur if the speaker discovers something about oneself, for instance from the behavior of others as in (13). ${ }^{7}$

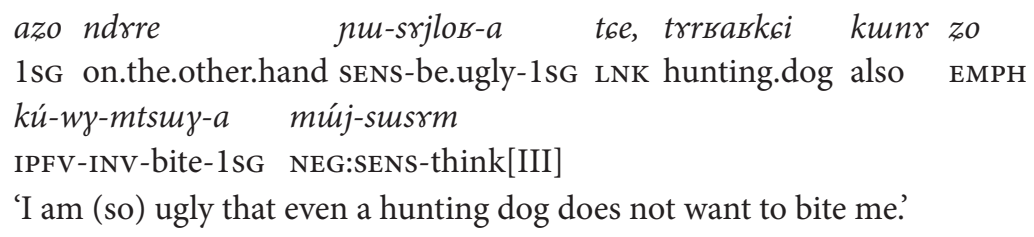

(translation, 140519 chou xiaoya, 86)

5. This verb should not be confused with the homophonous semi-transitive verb rga 'like', from which it is demonstrably distinct, even though both are borrowed from Tibetan dga.

6. As pointed out by an anonymous reviewer, this example is related to use of the Sensory prefix with endopathic predicates, as in (18).

7. This example is taken from the translation of Andersen's story 'The Ugly Duckling', when a hunting dog appears before the eponymous character but does not bite him. 
The Sensory is also used concerning information that is somehow part of common knowledge, but that the speaker has not had the opportunity to personally confirm. For instance, it is commonly used instead of the Factual for describing facts about animals that do not live in Tibetan areas and that the speaker only knows through indirect channels. Compare for instance the forms of the stative verbs $s \gamma \gamma$ - $m u$ 'be terrifying' and mp6rr 'be beautiful': they appear in the Factual when referring to spiders or flowers found in the area (14) and (16) and in the Sensory when referring to lions and gnus, which the speaker has only seen in zoos or on television (15) and (17).

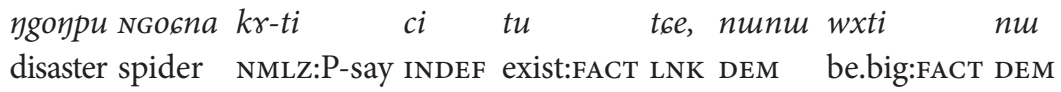
stó jamar tu kú-wy-rtos t6e sry-mu.

bean about exist:FACT IPFV-INV-look.at LNK DEEXP-be.afraid:FACT

'There is one that is called 'disaster spider', it is big, like the size of a bean. It is terrifying to look at.'

(26 mYaRmtsaR, 151)

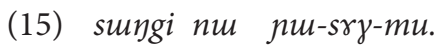

lion DEM SENS-DEEXP-be.afraid

'The lion is terrifying.'

(20 sWNgi, 64)

(16) пшпи ш-типтов пи трбrr.

DEM 3sG.Poss-flower DEM be.beautiful:FACT

'Its flower is beautiful.'

(15 babW, 105)

(17) <jiaoma> nu nu-mpсrr

gnu DEM sENs-be.beautiful

'The Gnu is beautiful.'

(20 RmbroN, 128)

As in other languages of the area (Tournadre \& LaPolla 2014), the Sensory form is used for endopathic sensations (pain, itch, cold, etc.) relating to the speaker, as in Example (18).
$t^{\text {ham }}$ toe mú-j-ch $a-a$,
$a-m i$
nu-mirm.

now LNK NEG:SENS-can-1SG 1sG.POSS-foot sENS-hurt

'Now I can't, my foot hurts.'

(21 kuGrummAG, 24)

Unlike in Lhasa Tibetan where the Sensory 'dug cannot be used for non-personal endopathic feelings (Tournadre \& LaPolla 2014), this possibility is available to the Japhug Sensory. In (19), the Sensory is used in a generic sentence, when the speaker has experienced himself the feeling and recounts his experience while presenting it as a generic fact, and thus this does not count as a real example of Sensory with non-first person. 

(19) $k m-m a q^{h} u \quad q^{h} e$ tw-6ga nu-mirm
NMLZ:S/A-be.after LNK GENR.POss-tooth sENs-hurt
'Afterwards teeth hurt.'

(27 tApGi, 66)

In Example (20), which describes the effects of foot and mouth disease on cattle, the speaker infers that the cattle suffering from the disease are in pain (because of their whining), yet uses the Sensory due to the fact that she describes an event she has directly witnessed by vision and hearing.

(20) nu-mci kr-rrwum maka múj-cha-nu t6e nu-mci

3PL.POss-saliva INF-collect at.all NEG:SENS-can-PL LNK 3PL.POss-saliva

tuIPFV-flow.continuously EMPH SENS-be LNK 3PL.POSs-throat sENS-hurt SFP 'They cannot keep the saliva in their mouths, and it flows continuously. Their throats hurt.'

(27-kharwut, 6)

In (21) likewise we have the Sensory used with myrm 'hurt' to describe an event visually witnessed by the speaker.

(21) kugnrsqi thu-azyut ri, t6e prjkh $u$ u-mi nu-myrm t6e ri, seventy PFV-reach but LNK already 3sG.POss-foot sENS-hurt LNK but nu kunr $k^{h} a$ tshitsuku nu-nrme $6 t$. DEM also house some.things SENS-work[III] be:AFFIRM:FACT 'He is seventy, his foot hurts already, but even like that he does all sorts of work at home.'

(14 : tApitaRi, 49-50)

\subsection{Egophoric}

The Egophoric, while common in conversations, is nearly non-existent in narrative and procedural texts (outside of quotations) unlike the Factual and the Sensory. It is used to describe information that is not directly shareable, which the speaker obtains through his own "personal involvement in a state of affairs" (Floyd 2018).

In declarative sentences, Egophoric can occur with first person, in particular with stative verbs whose subject is an experiencer (as $k u$-scit- $i$ 'we are happy' in (22); this is a very common form, independently heard in conversation, for instance in new year's greetings). It is however also compatible with third person, in the case of people from the same household, with whom the speaker shares his/her life (the king - the speaker's husband - and the servants in Example (22)), or with concrete or abstract nouns with a first person possessive prefix (as $а$-ва 'my free time' in (23)). This usage is similar to the so-called "broad scope" egophoric observed in Lhasa Tibetan and other Tibetic languages (Gawne 2017: 89). 
(22) t6 ${ }^{h}$ eme nu ku 'wuma zo ku-scit-i, rfrlpu ri girl DEM ERG really EMPH PRS:EGOPH-be.happy-1PL ROI also a-tав wuma ku-sna вјов ra ri wuma zo 1sG-on really PRS:EGOPH-be.kind servant PL also really EMPH ku-pe-nu' to-ti, PRS:EGOPH-be.good IFR-say

'The girl said: "We are very happy, the king is very kind to me, the servants are very nice."' (The frog 2002, 122-124)
azo kure a-sa
ku-me tw-mgo

1SG here 1sG.POss-free.time PRS:EGOPH-not.exist INDEF.POSs-food ku-osu- $\beta z u-a$ 6ti

PRS:EGOPH-PROG-make-1sG be.AFFIRM:FACT

'I don't have time, I am making food.'

(Rkangrgyal, 47)

There is no syntactic rule requiring co-occurrence of egophoric marking with a first person subject or a subject with first person possessor. As shown by Example (24) with the collocation $u$-grrl+me (one of whose meanings is 'be innumerable'), the Egophoric can occur even if no first person marker is present in the clause. ${ }^{8}$

$$
\text { 6a } u-n d z a \quad u-g r r l \quad k u-m e
$$

meat 3SG-BARE.INF:eat 3sG.POSS-order PRS:EGOPH-not.exist

'There is an immense amount of meat to eat.'

(2003 kandZislama, 129)

No example of Egophoric with second person subject in declarative sentences has been found in the corpus, nor could such an example be elicited.

In the case of experiencer stative verbs such as scit 'be happy' with a first person subject, there is a tripartite contrast between Egophoric, Sensory, and Factual. The following near-minimal pairs can help understand how each form is used in such a context.
nut6u nu-scit-a
$6 t i$
li the t6e

DEM:LOC SENS-be.happy-1sg be.AFFIRM:FACT again LNK LNK $a-z d a$ ri nu-pe-nu, 1sG-companion also sENs-be.good-PL

'I am very happy there, the people with me are very nice.' (140501 jingli, 149)

8. Example (24) is a sentence pronounced in the story by a raven, who tells another raven that due to an infectious disease, a lot of cattle from nomad areas died, so there is a lot of meat to eat. The use of egophoric here implies that it has partaken in the feast, rather than being simply witness of the fact. 
(26) nu tr-yu t6e azo ndrre, slonbutchi srz DEM PFV-be LNK 1SG on.the.other.hand elephant COMP ndrre nu-scit-a t6e $a-k^{h}$ nu-ngm on.the.other.hand sENs-be.happy-1sG LNK 1sG.POss-luck sENs-be.lucky 'Since it is like that, I am happier than the elephant, I am luckier than him.' (translation, 140425 shizi puluomixiusi he daxiang, 41)

(27) хsw-хра jr-tsu-j, nusthuci zo scit-i, three-year PFV-pass-1sG so.much EMPH be.happy:FACT-1PL amumi-j

be.in.good.terms:FACT-1PL

'We have been together for three years now, we are so happy together.'

(Norbzang 2005, 95)

In (27), the speakers (humans stranded on an island) include the addressees (râkshasîs in human shape) in the first plural, and state their happiness together as a commonly agreed fact (the first step in a plan to cheat the râkshasîs), hence the use of the Factual.

In (26), the speaker, after a discussion, realizes that he is happier than the lion, and therefore chooses the Sensory. In (25) the use of the Sensory rather than the Egophoric is more subtle; the speaker, talking about her life at work, does not suddenly realizes that she is happy at work. Rather, she expressed that when thinking about it, she feels that she is happy, as opposed to the continuous consciousness of being in a state of happiness implied by the use of the Egophoric in (22).

\subsection{Japhug and Tibetan}

The tripartite Japhug evidential system in present tense is very similar to the one observed in Tibetic languages such as Lhasa Tibetan between the Imperfective Factual gi.yod.pa.red, Sensory gis and Egophoric gi.yod (Tournadre 2008: 295296), ${ }^{9}$ though with minor differences in the use of Sensory for endopathic sensations (see Example (18) above). Surprisingly, the Japhug evidential categories are actually more similar to those of Lhasa Tibetan than some Tibetic varieties like Yolmo are (on which see Gawne 2013).

9. Hill \& Gawne (2017) propose to replace 'egophoric' by 'personal' and 'sensory' or 'testimonial' by 'experiential', but in the interest of continuity with previous publications on Rgyalrong languages, I shall keep the terminology used in Jacques (2017). 


\subsection{The expression of surprise}

Given the debated status of the expression of surprise and its relationship to evidentiality (Hill 2012; DeLancey 2012; Aikhenvald 2012), it is useful to provide data on the mirative use of the Sensory evidential in Japhug.

Japhug has two interjections specifically used to express surprise (amay and $m t^{h} h r i$, the second being of Tibetan origin). When the predicate of the sentence is a stative verb, it is possible to select the Sensory evidential as in (28), as expected for a visual perception. This use of the Sensory evidential is what motivated its analysis as a mirative marker in some languages (Hill 2012).

(28) amay, nust ${ }^{h} u c i$ nu-mbro

INTERJECTION:SURPRISE SO.much SENS-be.high

'It is so high!' (translation, 150826 liyu tiao longmen, 75)

Another possibility is to use a non-finite verb form, the degree noun (built by combining a possessive prefix coreferent with the subject with the -tu-nominalization prefix, see Jacques 2016b: 10-11), focusing on the surprisingly high degree of the observed property as in Example (29).

amay, $\quad$ nu $u$-tu-srre,

INTERJECTION:SURPRISE DEM 3SG-NMLZ:DEGREE-be.funny

mtshrri, u-tu-srmtshrr nu

INTERJECTION:SURPRISE 3SG-NMLZ:DEGREE-be.surprising SFP

'It is so funny, so surprising!' (translation, 150830 baihe jiemei, 112)

\section{Interrogative clauses}

Like most languages of the Tibetosphere, interrogative sentences generally adopt the perspective of the addressee rather than that of the speaker, causing a phenomenon referred to as 'anticipation rule' (Tournadre \& LaPolla 2014: 244) or 'flipping' (San Roque et al. 2017): the speaker anticipates the answer of the addressee and uses the form that he expects the addressee will choose in responding to the question. For instance, in Example (30), the speaker uses the Factual because she expects an answer with the Factual such as suz-a know:FACT-1sG 'I know'.

(30) $n r j i u-t u ́-s u z ?$

2SG QU-2-know:FACT

'Do you know that?'

(19 GzW, 8)

As a result of this change of perspective, compatibilities between evidential markers and first vs second person are always reversed between declarative and interrogative 
sentences. In particular, as discussed in $\$ 2.3$, the Egophoric is used with a first person subject or a third person subject with first person possessor (or belonging to the same household as the speaker) in declarative sentences, never with a second person subject. In interrogative sentences, this person constraint is reversed: the Egophoric appears with second person subject (as in Example (31)) or third person with second person possessive prefix.

\section{(31) ' 'u-kú-tu-scit-nu?' ra to-ti, QU-PRS:EGOPH-2-be.happy-PL PL EVD-say}

She said: 'Are you (and your husband) happy?'

(The frog 2002, 121)

The addressee perspective however is not a syntactic rule. The addressee is free to adopt the evidential form suggested by the speaker who asked the question, or to choose another form if he sees fit: see Garrett \& Bateman (2007) for an account of this phenomenon in Tibetan. It is also possible to have in the same question two verbs referring to the addressee with the Egophoric in one case and the Sensory in the other, as in (32).

(32) wo, u-kú-tu-pe, $u-n u ́-t u-c^{h} a \quad$ nura ntsw to-ti

INTERJ QU-EGOPH:PRS-2-be.good QU-SENS-2-be.fine DEM:PL always IFR-say '(The fox) said (to the deer) 'Are you feeling well, are you fine?'

(translation, 140425 shizi huli he lu, 16)

Sentences (33) and (34) illustrate the difference of use of the Sensory and Egophoric forms in third person subject interrogative contexts. These questions expect answers in the Sensory and Egophoric forms respectively. Question (33) was asked when I phoned from my parents' home (when I came for the holidays). The Sensory is used because my parents and I do not live in the same household, and the expectation was that I had just realized whether or not they were well after having arrived at their place.

Question (34) on the other hand, asked about my son, expects an answer in the Egophoric because since I live with him in the same house, I always know whether he is fine or not (I did not 'discover' whether he was fine at a certain point).

(33) $n \gamma-m u$ $n \gamma-w a$ ni u-nú-pe-ndżi?

2sG.Poss-mother 2sG.POss-father DU QU-SENS-be.good-DU 'Are your parents well?'

(conversation 2014.12)

$n \gamma-t \in u \quad u-k u ́-p e ?$

2sG.POSS-son QU-EGOPH-be.good

'Is your son well?'

(conversation 2014.02)

The Factual would not be appropriate in these contexts because neither involve a permanent state part of common knowledge. 


\section{Reported speech}

Hybrid Indirect Speech is a well-established feature of Tibetic languages (Tournadre 2008), and has also been documented in Gyalrongic languages, in particular Japhug (Jacques 2016a: 241-244) and Stau (Jacques et al. 2017). Examples (35) and (36), taken from Jacques (2016a: 242-3), illustrate the effects of Hybrid Indirect Speech on person indexation and pronouns. As in Tibetan, the verb form represents the point of view of the original speaker (highlighted in blue in the following examples), while the pronouns and possessive prefixes represent that of the current speaker (highlighted in red).

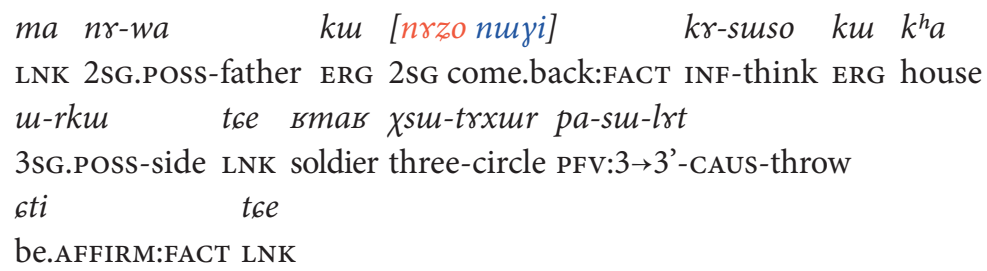

Direct: 'Your father, thinking "He is coming back", put three circles of soldiers around the house.'

Indirect: 'Your father, thinking that you are coming back,'

Hybrid indirect: 'Your father, thinking that "you" is coming back,'

(qachGa 2003, 154)

In (35), the 2sG pronoun $n$ rzo normally requires a verb in second person form tu-nuyi 2-come.back:FACT 'you are coming back'; the use of the third person nuyi 'he is coming back' reflects the point of view of the original speaker (the father), while the pronoun $n \gamma z 0$ represents that of the current speaker. Example (36) shows that the shift in speaker perspective applies not only to pronouns, but also to possessive prefixes.

(36) t6endrre ta-вi

$n w \quad k w \quad[u-p i \quad \gamma w$ LNK INDEF.POss-younger.sibling DEM ERG 3sG.POss-elder.sibling GEN u-sci tu-nrme-a ra] jr-suso t6e, 3sG.POss-revenge IPFV-make[III]-1sG have.to:FACT IFR-think LNK

Direct: 'The (younger) sister thought "I have to get revenge on my brother"' Indirect: 'The (younger) sister ${ }_{i}$ wanted to get revenge on her ${ }_{i}$ brother.' Hybrid indirect: 'The (younger) sister ${ }_{i}$ thought $\mathrm{I}_{i}$ have to get revenge on her ${ }_{i}$ brother' (translation, xiong he mei, 17)

The presence of Hybrid Indirect Speech is never obligatory; Direct Speech is always a possibility, and moreover since pronouns are not overt in most quotations in our 
corpus, it is rarely possible to distinguish between the two, since the verb form, the only obligatory element, will be the same regardless. ${ }^{10}$

The shift of viewpoint caused by Hybrid Indirect Speech has effect not only on person marking, but also on person-sensitive evidential marking.

Examples (37) and (38) are from two versions of the same story, translated from Chinese. The first translation (37), uses Direct Speech: $a-t_{6}{ }^{h} a$ maka $k u-m e$ 'I do not have any news': the possessor of the inalienably possessed abstract noun $-16^{h} a$ corresponds (in this construction with an existential verb) to the person who receives the information, not the person whom the information is about. ${ }^{11}$

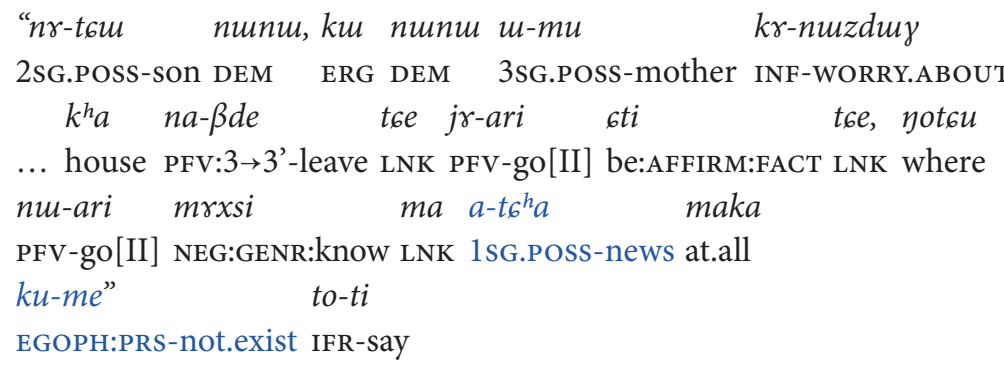

'Your son left out of grief, I don't know where he went, I don't have any news (from him).'

(translation, fushang he yaomo, 101-103)

The second version (38) uses Hybrid Indirect Speech, and we observe a mismatch between the possessive prefix on the noun $u-t 6^{h} a$ (third person) and the Egophoric form of the predicate.

\begin{tabular}{|c|c|c|c|c|}
\hline 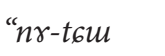 & nunu kw & пшпш & $u-m u$ & $k \gamma-n u z d u \gamma$ \\
\hline 2sG.POSS-SO & ON DEM & DEM & 3sG.POSs-mother & INF-WORRY.ABOU \\
\hline 6e kha & $n a-\beta d e$ & $t_{6 e}$ & $j \gamma-a<n u>r i$ & 6ti $t_{6 e}$ \\
\hline $\begin{array}{l}\text { LNK house } \\
m-t_{6}^{h} a\end{array}$ & $\begin{array}{c}\text { PFv: } 3 \rightarrow 3 \text { '-leave } \\
k u-m e^{\prime \prime}\end{array}$ & LNK & $\begin{array}{c}\mathrm{PFV}-<\mathrm{AUTO}>\mathrm{gO}[\mathrm{II}] \\
n w-t i \quad 6 t i .\end{array}$ & AFFIRM:FACT LNK \\
\hline
\end{tabular}

3SG.POSS-news EGOPH:PRS-not.exist SENS-say AFFIRM:FACT

'Your son left out of grief, he went (away) on his own,

Direct: 'I don't have any news (from him).'

Indirect: She (his wife) does not have any news (from him).

Hybrid indirect: She (his wife) don't have any news (from him).

(translation, fushang he yaomo1, 114-116)

10. Indirect Speech is also marginally attested in translations from written Chinese.

11. In the original text, the corresponding clause 一直没有消息 'there has not been any news (since then)' has no explicit person marker; person marking and evidential markers here cannot be due to calquing from Chinese. 
In this construction, the possessive prefix on $-t 6^{h} a$ can only refer to the person who receives the information, not the person the information is about. Thus, a sentence such as (39) cannot be translated as ' $\mathrm{X}$ did not receive any news from him'.

$$
u-t_{6}^{h} a \quad \text { pu-me }
$$

3sG.POSS-news PST.IPFV-not.exist

'He has not received any news/answers.'

(elicited)

The verb form $\mathrm{ku}$-me with the Egophoric represents the point of view of the original speaker (the first wife), while the possessive prefix on the noun represents the point of view of the current speaker, for whom the original speaker is third person. ${ }^{12}$

Example (40) illustrate the converse situation, with the Sensory used with the first person. The verb $n u-k^{h} e$ 'he is stupid' is a third person form in the Sensory, while the pronoun $a z o$ is first person (in direct speech, the third person pronoun uzo 'he' instead would have been expected).

$$
\begin{array}{lll}
\text { azo } & n m-k^{h} e \quad a-m \gamma-n u-s w s o-n m \\
1 \text { SG } & \text { SENS-be.stupid IRR-NEG-PFV-think-PL }
\end{array}
$$

Direct: 'Let us hope that they will not think, "He is stupid".

Indirect: 'Let us hope that they will not think that I am stupid.'

Hybrid indirect: 'Let us hope that they will not think that I is stupid.'

(translation, huangdi de xinzhuang)

In addition to mismatch in person indexation, the evidential form of the verb - the Sensory nu- - also expresses the point of view of the original speaker, namely the words that the current speaker attributes to other people. It does not imply that the speaker discovers a fact about himself (unlike examples like (13) above), since he does not consider himself to be stupid.

Future research on Japhug narratives will hopefully reveal converse examples with a verb in Egophoric form in reported speech combined with a third or second person pronoun or possessive prefix.

12. Note however that the first sentence in Example (38) is in Direct Speech, as shown by the second person prefix $n \gamma$ - on the noun - $t 6 w$ 'son'. If this sentence were in Hybrid Indirect Speech, we would instead have the perspective of the current speaker, and use a first person possessive prefix $a$-t6u 'my son'. 


\section{Conclusion}

This paper is the first step towards a comprehensive description of the evidential system in Japhug, and of that of Rgyalrong languages in general. Focusing on a narrow topic, stative verbs in present tense, it presents the use of the tripartite evidential system in this context (Factual, Sensory, Egophoric) and their interaction with person indexation. It shows that the use of the Egophoric marker in declarative clauses, interrogative clauses and reported speech cannot be described by a syntactic rule, and is only indirectly related to person indexation. Future research will have to study the evidential contrasts of Stative verbs in past tense, and then extend this study to dynamic intransitive and transitive verbs.

Japhug and other Rgyalrong languages, which combine a Tibetan-like evidential system with polypersonal indexation on the verb, provide a testing ground for studying the interaction between evidentiality and person in cross-linguistic perspective.

\section{Acknowledgements}

This research was funded by the HimalCo project (ANR-12-CORP-0006) and is related to the research strand LR-4.11 "Automatic Paradigm Generation and Language Description" of the Labex EFL (funded by the ANR/CGI). I would like to thank Marc Bavant, Lauren Gawne, Simeon Floyd, Nathan W. Hill, Theo Lap, Holger Markgraf, Alexis Michaud, Nicolas Tournadre and two anonymous reviewers for useful comments on previous versions of this work.

\section{Abbreviations}

$\begin{array}{llll}\text { AUTO } & \text { autobenefactive-spontaneous } & \text { IFR } & \text { inferential } \\ \text { ANTICAUS } & \text { anticausative } & \text { INDEF } & \text { indefinite } \\ \text { ANTIPASS } & \text { antipassive } & \text { INV } & \text { inverse } \\ \text { APPL } & \text { applicative } & \text { LNK } & \text { linker } \\ \text { DEM } & \text { demonstrative } & \text { PFV } & \text { perfective } \\ \text { DIST } & \text { distal } & \text { POSS } & \text { possessor } \\ \text { EMPH } & \text { emphatic } & \text { PRES } & \text { egophoric present } \\ \text { FACT } & \text { factual } & \text { PROG } & \text { progressive } \\ \text { GENR } & \text { generic } & \text { SENS } & \text { sensory }\end{array}$




\section{References}

Aikhenvald, Alexandra. 2004. Evidentiality. Oxford: Oxford University Press.

Aikhenvald, Alexandra. 2012. The essence of mirativity. Linguistic Typology 16(3). 435-485. https://doi.org/10.1515/lity-2012-0017

Aikhenvald, Alexandra. 2015. Evidentials: Their links with other grammatical categories. Linguistic Typology 19(2). 239-277. https://doi.org/10.1515/lingty-2015-0008

Bendix, Edward. 1974. Indo-Aryan and Tibeto-Burman contact as seen through Nepali and Newari verb tenses. International Journal of Dravidian Linguistics 3(1). 42-59.

Creissels, Denis. 2008. Person variations in Akhvakh verb morphology: Functional motivation and origin of an uncommon pattern. Sprachtypologie und Universalienforschung 61(4). 309-325.

Curnow, Timothy Jowan. 2002. Conjunct/disjunct systems in Barbacoan languages. In Castillo, Jeannie (ed.), Proceedings from the fourth Workshop on American Indigenous Languages (Santa Barbara Papers in Linguistics 11), 3-12. Santa Barbara: UCSB, Department of Linguistics.

Daudey, Henriëtte. 2014. Volition and control in Wadu Pumi. Linguistics of the Tibeto-Burman Area 37(1). 75-103. https://doi.org/10.1075/ltba.37.1.03dau

DeLancey, Scott. 1990. Ergativity and the cognitive model of event structure in Lhasa Tibetan. Cognitive Linguistics 1(3). 289-321. https://doi.org/10.1515/cogl.1990.1.3.289

DeLancey, Scott. 2012. Still mirative after all these years. Linguistic Typology 16(3). 529-564.

DeLancey, Scott. 2018. Evidentiality in Tibetic. In Aikhenvald, Alexandra (ed.), The Oxford handbook of evidentiality. Oxford: Oxford University Press.

Floyd, Simeon. 2018. Egophoricity and argument structure in Cha'palaa. In Floyd, Simeon \& Norcliffe, Elisabeth \& San Roque, Lila (eds.), Egophoricity, 269-304. Amsterdam: Benjamin. https://doi.org/10.1075/tsl.118.09flo

Floyd, Simeon \& Norcliffe, Elisabeth \& San Roque, Lila (eds.). 2018. Egophoricity. Amsterdam: John Benjamins. https://doi.org/10.1075/tsl.118

Garrett, Edward \& Bateman, Leah. 2007. Symbiosis between documentary linguistics and linguistic pragmatics. In Austin, Peter K. \& Bond, Oliver \& Nathan, David (eds.), Proceedings of Conference on Language Documentation and Linguistic Theory, 83-93. London: School of Oriental and African Studies, University of London.

Gawne, Lauren. 2013. Lamjung Yolmo copulas in use: Evidentiality, reported speech and questions. Melbourne: University of Melbourne. (Doctoral dissertation.)

Gawne, Lauren. 2017. Egophoric evidentiality in Bodish languages. In Hill, Nathan W. \& Gawne, Lauren (eds.), Evidential systems of Tibetan languages, 61-94. Berlin: Mouton de Gruyter. https://doi.org/10.1515/9783110473742-003

Hale, Austin. 1980. Person markers: Finite conjunct and disjunct verb forms in Newari. In Trail, R. L. (ed.), Papers in South-East Asian linguistics, vol.7, 95-106. Canberra: Australian National University.

Hill, Nathan W. 2012. "Mirativity" does not exist: hdug in "Lhasa" Tibetan and other suspects. Linguistic Typology 16(3). 389-433. https://doi.org/10.1515/lity-2012-0016

Hill, Nathan W. \& Gawne, Lauren. 2017. The contribution of Tibetan languages to the study of evidentiality. In Hill, Nathan W. \& Gawne, Lauren (eds.), Evidential systems of Tibetan languages, 1-38. Berlin: Mouton de Gruyter. https://doi.org/10.1515/9783110473742-001 
Jacques, Guillaume. 2012. Agreement morphology: The case of Rgyalrongic and Kiranti. Language and Linguistics 13(1). 83-116.

Jacques, Guillaume. 2014. Clause linking in Japhug Rgyalrong. Linguistics of the Tibeto-Burman Area 37(2). 264-328. https://doi.org/10.1075//tba.37.2.05jac

Jacques, Guillaume. 2016a. Complementation in Japhug. Linguistics of the Tibeto Burman Area 39(2). 222-281. https://doi.org/10.1075/ltba.39.2.02jac

Jacques, Guillaume. 2016b. From ergative to comparee marker: Multiple reanalyses and polyfunctionality. Diachronica 33(1). 1-30. https://doi.org/10.1075/dia.33.1.01jac

Jacques, Guillaume. 2017. Japhug. In Thurgood, Graham \& LaPolla, Randy (eds.), The SinoTibetan languages, 2nd edn., 614-634. London: Routledge.

Jacques, Guillaume \& Antonov, Anton \& Lai, Yunfan \& Nima, Lobsang. 2017. Stau (Ergong, Horpa). In Thurgood, Graham \& Randy LaPolla (eds.), The Sino-Tibetan languages, 2nd edn., 597-613. London: Routledge.

Lin, Youjing. 2003. Tense and aspect morphology in the Zhuokeji rGyalrong verb. Cahiers de Linguistique-Asie Orientale 32(2). 245-286. https://doi.org/10.3406/clao.2003.1633

Michailovsky, Boyd \& Mazaudon, Martine \& Michaud, Alexis \& Guillaume, Séverine \& François, Alexandre \& Adamou, Evangelia. 2014. Documenting and researching endangered languages: The Pangloss Collection. Language Documentation and Conservation 8. 119-135.

San Roque, Lila \& Floyd, Simeon \& Norcliffe, Elisabeth. 2017. Evidentiality and interrogativity. Lingua 186-187. 120-143. https://doi.org/10.1016/j.lingua.2014.11.003

San Roque, Lila \& Loughnane, Robin. 2012. The New Guinea Highlands evidentiality area. Linguistic Typology 16(1). 111-167. https://doi.org/10.1515/lity-2012-0003

Sun, Jackson T.-S. 2000. Parallelisms in the Verb Morphology of Sidaba rGyalrong and Lavrung in rGyalrongic. Language and Linguistics 1(1). 161-190.

Sun, Jackson T.-S. 2003. Caodeng rGyalrong. In Thurgood, Graham \& LaPolla, Randy (eds.), The Sino-Tibetan languages, 490-502. London: Routledge.

Sun, Jackson T.-S. 2018. Evidentials and person. In Aikhenvald, Alexandra (ed.), Oxford handbook of evidentiality, 47-63. Oxford: Oxford University Press.

Tournadre, Nicolas. 1996. L'ergativité en tibétain [Ergativity in Tibetan]. Louvain: Péeters.

Tournadre, Nicolas. 2008. Arguments against the concept of 'conjunct'/ 'disjunct' in Tibetan. In Huber, Brigitte \& Volkart, Marianne \& Widmer, Paul (eds.), Chomolangma, Demawend und Kasbek: Festschrift für Roland Bielmeier zu seinem 65. Geburtstag [Chomolangma, Demawend and Kasbek: Festschrift for Roland Bielmeier on his 65th birthday], 281-308. Halle: International Institute for Tibetan and Buddhist Studies.

Tournadre, Nicolas \& LaPolla, Randy. 2014. Towards a new approach to evidentiality. Linguistics of the Tibeto-Burman Area 37(2). 240-263. https://doi.org/10.1075/ltba.37.2.04tou

Van Driem, George. 1993. A grammar of Dumi. Berlin: Mouton De Gruyter. https://doi.org/10.1515/9783110880915

Widmer, Manuel \& Zemp, Marius. 2017. The epistemization of person markers in reported speech. Studies in Language 41(1). 33-75. https://doi.org/10.1075/sl.41.1.02wid

Yukawa, Yasutoshi. 1971. Chibettogo no jutsubu no rinkaku [Outline of Tibetan predicates]. Gengogaku no kihon mondai [Basic problems in linguistics], 178-204. Tokyo: Taishūkan Shoten. 
Author's address

Guillaume Jacques

Southwest University (ICLD) \& CNRS (CRLAO)

21 rue de la glacière

75013 Paris

France

rgyalrongskad@gmail.com

\section{Publication history}

Date received: 4 September 2017

Date accepted: 24 October 2017 